\title{
AS ROCHAS ULTRABÁSICAS DA SERRA DO ESPINHAÇO, MG
}

\author{
FRIEDRICH RENGER*
}

ABSTRACT An alpine-type "serpentine belt", situated in the transition zone between the mioand eugeosyncline of the Premcambrian Minas Series in the State of Minas Gerais, Brazil, shows an extension of at least $300 \mathrm{~km}$. From petrographic evidence, a four step evolution and alteration scheme can be deduced:
1) peridotite;
2) serpentinization;
3) chloritization and amphibolization;
4) talquification + carbonatization.

Some of the ultrabasic bodies show a chromite mineralization with economic possibilities in part. Regional correlations may indicate a major extension of this "serpentine belt", specially to the north, accompanying the quartzites of the Minas Series.

INTRODUÇÃo A Serra do Espinhaço meridional estende-se rumo norte desde o Quadrilátero Ferrífero por uns $300 \mathrm{~km}$. É constituída essencialmente de quartzitos com intercalações de filitos e conglomerados intraformacionais da Série Minas (Pflug, 1965; 1968; Pflug et al., 1969).

Foram mencionadas várias ocorrências de rochas ultrabásicas metamorfoseadas, entretanto, nenhuma das referências contém um estudo mais pormenorizado da situação geológica e petrográfica (Moraes, 1937; O. Barbosa, 1949; 1954; Costa, 1952; Alves, 1952; Belezkij e Guimarães, 1959). Essas ocorrências também não foram mencionadas numa recente compilação das rochas ultrabásicas do Brasil (Scorza, 1968).

Através de um levantamento sistemático da Serra do Espinhaço meridional, na escala $1: 100000$, foram encontrados inúmeros afloramentos de rochas ultrabásicas, localizados imediatamente a leste da região montanhosa da serra (Renger, 1970a; Gorlt, no prelo; Kehrer, no prelo). Tais rochas formam uma faixa estreita de mais ou menos 10 a $15 \mathrm{~km}$ de largura, acompanhando a direção dos quartzitos e filitos da facies miogeossinclinal e os micaxistos e gnaisses da facies eugeossinclinal, podendo ser seguida desde Rio Vermelho, ao sul da Serra Negra, passando por Santo Antônio do Itambé, Serro, Dom Joaquim, perto de Conceição do Mato Dentro, Morro do Pilar, até Itabira. Assim, ela alcaņ̧a uma extensão de mais de $150 \mathrm{~km}$ (Fig. 1).

Os ultrabasitos formam maciços irregulares sob forma de stocks de tamanho variável, desde algumas centenas de metros até aproximadamente $10 \mathrm{~km}$ de extensão. Muitas vezes mostram uma xistosidade bastante acentuada, especialmente nas partes externas, enquanto que as partes internas, em muitos casos, apresentam-se maciças. A xistosidade coincide com a das rochas encaixantes, formadas por filitos, mica-xistos e gnaisses da Série Minas. Elas contêm inúmeras intercalações de xistos verdes ou anfibolitos com espessuras variáveis entre poucos decímetros e 5 a $10 \mathrm{~m}$. Dentro dos quartzitos não foram encontradas rochas ultrabásicas (veja a Fig. 2).

As condições dos afloramentos na região não permitem, infelizmente, estudos pormenorizados dos contatos; isso é devido à meteorização bastante profunda, que atinge

*Instituto Eschwege, Diamantina MG - Convênio Brasil-Alemanha. 


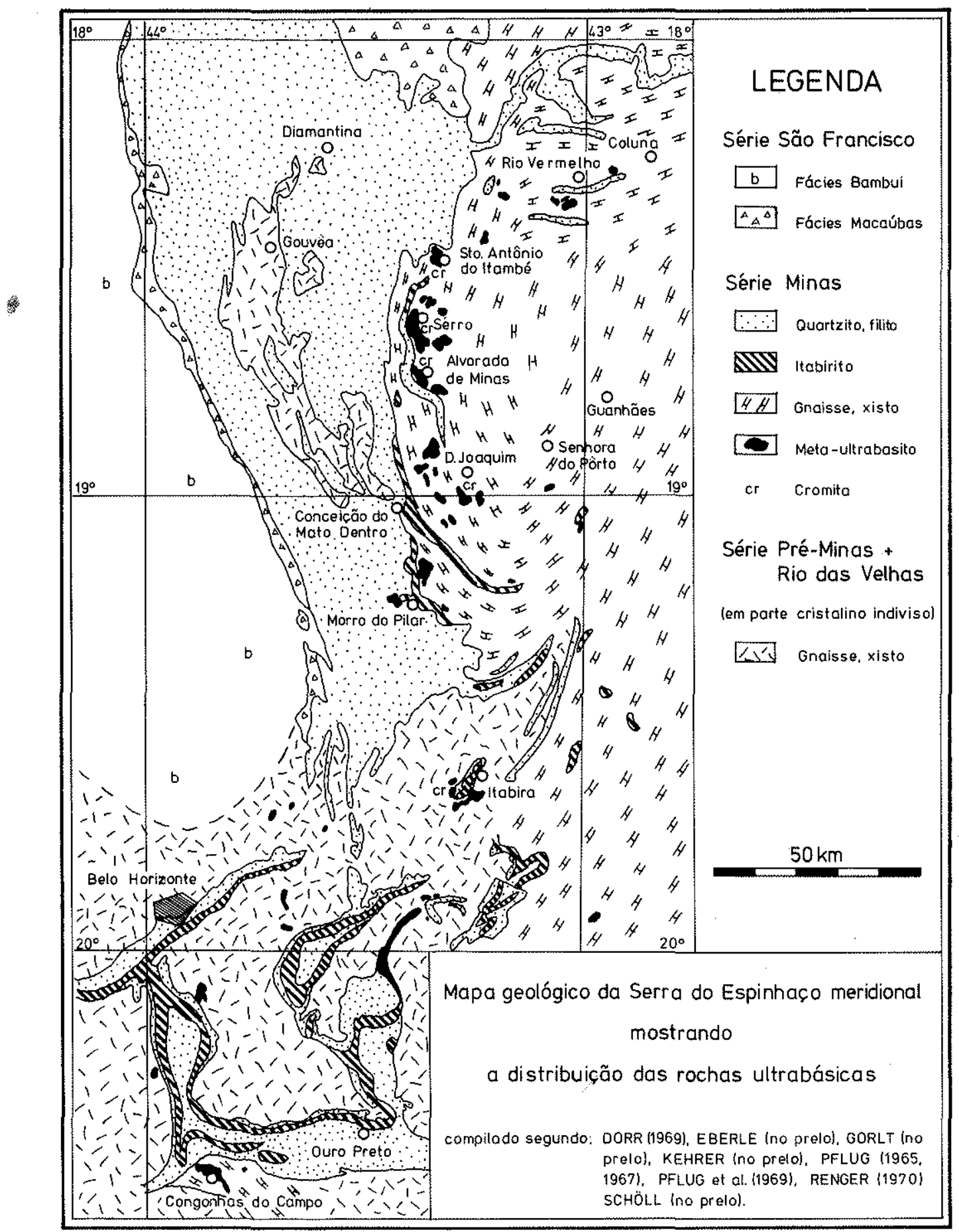

Figura 1 - Mapa geológico da Serra do Espinhaşo meridional e do Quadrilátero Ferxífero, MG, mostrando a distribuição das rochas ultrabásicas 


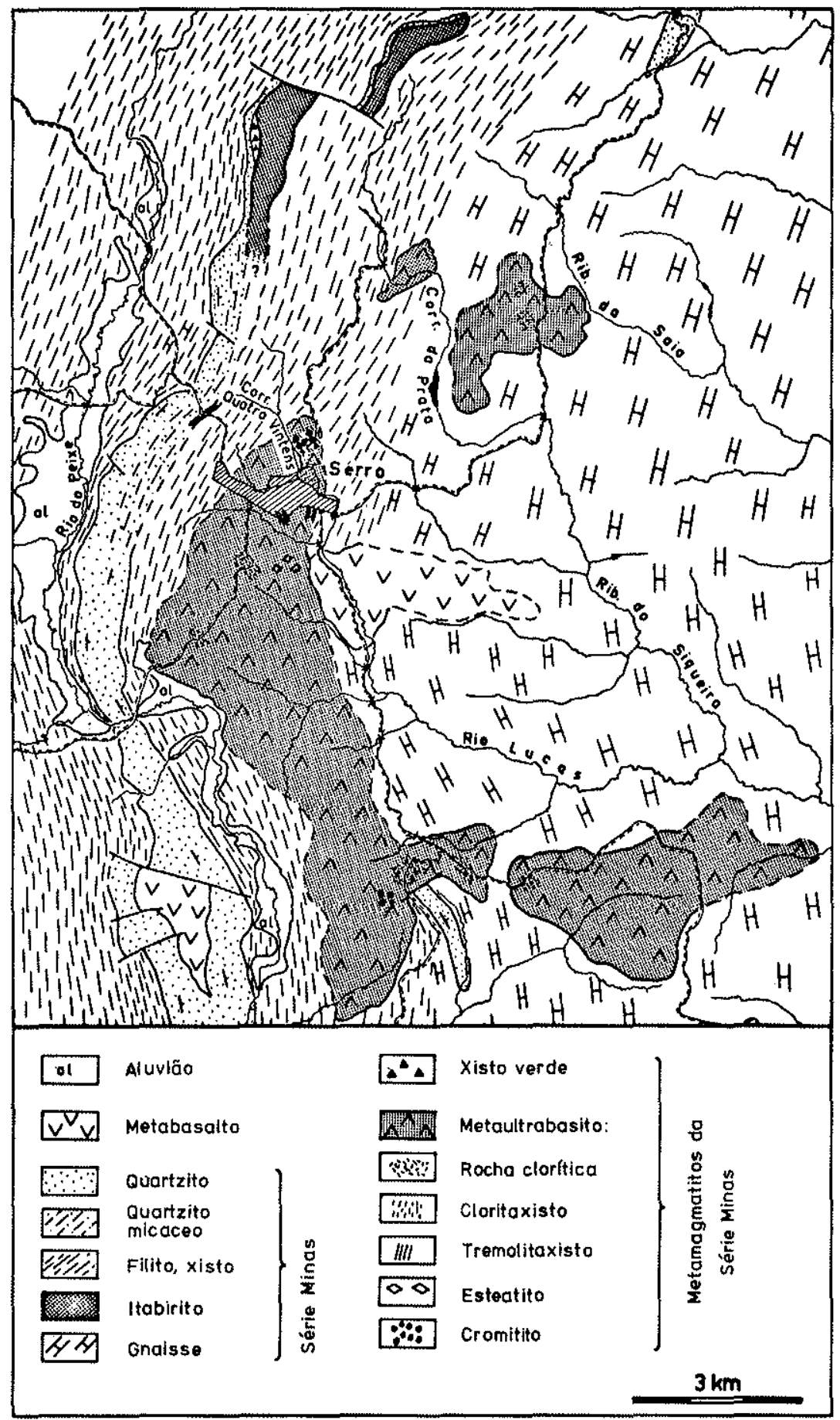

Figura 2 - Mapa geológico da região de Serro, MG 
tanto as rochas encaixantes como os ultrabasitos, produzindo um espesso manto de solo vermelho.

A composição das rochas ultrabásicas apresenta-se bastante variável, sendo que predominam minerais secundários, a saber: clorita, antigorita, tremolita, talco, magnesita e, às vezes, antofilita. Entretanto a pedra-sabão é a rocha mais típica dessa associação.

No caso das rochas em discussão, consideramos mais conveniente manter o termo "ultrabasito", que significa uma classificação química, enquanto que o termo "ultramafito" exige uma determinada composição mineralógica relacionada ao índice de coloração. Devido às alterações metamórficas, essa última muda consideravelmente, enquanto que a composição química se conserva mais ou menos constante.

Petrografia As cloritas apresentam-se nas lâminas delgadas em palhetas finíssimas de aproximadamente $0,01 \mathrm{~mm}$ até cristais com cerca de $0,1 \mathrm{~mm}$. Mostram um pleocroísmo, variando desde quase incolor ao verde-claro ou verde-azulado. $\mathrm{O}$ sinal óptico pode ser tanto positivo como negativo. As cores de interferência variam igualmente entre normal e anormal, mostrando um marron-escuro e um intenso azul. Revelou a difratometria de raios X tratar-se de cloritas com células unitárias de $14 \AA$, i.e., predominantemente cloritas ferro-magnesianas da série peninita - clinocloro - grochauita.

São esparsas as ocorrências de serpentina ou serpentinito, respectivamente. Restos de serpentinito mostram muitas vezes as texturas reticulares, típicas da serpentinização de olivina ou piroxênio, mesmo quando a serpentina já se apresenta alterada em clorita (Fig. 3).

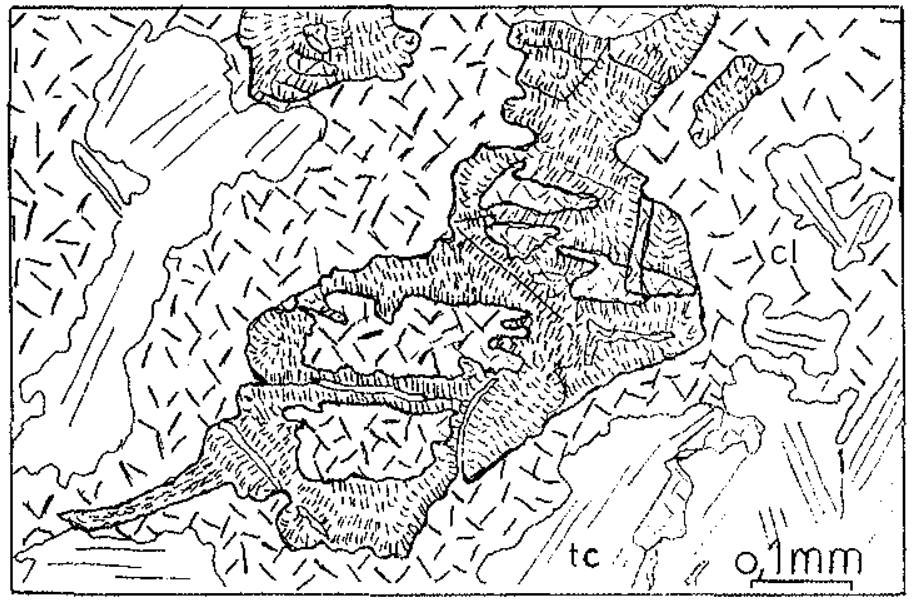

Figura 3 - Textura reticular como remanescente da serpentinização. A textura é formada por uma poeira fina de minerais opacos (magnetita?), sendo substituída a serpentina pela clorita (cl). A clorita, por sua vez, encontra-se em substituição pelo talco (ic). Procedência: a cerca de $8 \mathrm{~km}$ E de Dom Joaquim, estrada para Conceição de Mato Dentro

Através de transições, a clorita passa a antigorita, quase sempre ferrifera, apresentando um ligeiro pleocró́smo. Porém é muito difícil separar os dois minerais somente com o auxílio do microscópio e sem análises químicas. Crisolita nunca foi observada.

Entre os anfibólios encontram-se, predominantemente, os do grupo tremolita-actinolita, formando cristais equidimensionais de, aproximadamente, $0,25 \mathrm{~mm}$ ou aciculares de até $1 \mathrm{~mm}$. Os maiores mostram, às vezes, estruturas poiquiloblásticas com inclusões 
do mesmo mineral. A coloração varia entre incolor e o verde-claro, predominando o componente tremolítico.

Além desses, as rochas ultrabásicas contêm um ortoanfibólio que forma cristais de até $2 \mathrm{~mm}$ aproximadamente, em geral aciculares, não mostrando pleocróismo. Os cristais podem ser orientados segundo a xistosidade ou cortam a mesma num ângulo variável. Esses últimos mostram geralmente um alto grau de idiomorfismo. Trata-se de antofilita, um mineral típico de rochas ultrabásicas metamorfoseadas. A antofilita é restrita às ocorrências no extremo NE da faixa, nos arredores de Rio Vermelho e Coluna (Gorlt, no prelo).

Talco, de granulação fina, muitas vezes acompanha a clorita sob forma de escamas de igual tamanho, às vezes intercalado em camadas de 0,1 até $\pm 1 \mathrm{~mm}$. Em camadas mais espessas, o talco pode ser bem recristalizado. Às vezes é intercrescido, substituindo a clorita. Uma outra forma de apresentação do talco são palhetas maiores de 1 a $2 \mathrm{~mm}$ cortando a xistosidade sem qualquer orientação preferencial. Ocorrem também veios de talco puro, desde poucos milímetros até vários centímetros, igualmente sem uma orientação. Nesses veios, encontram-se cristais singulares de talco de até $\pm 10 \mathrm{~cm}$, de coloração verde-claro esbranquiçada.

Carbonalo ć um constituinte muito comum, especialmente em rochas mais ricas em talco, formando, associado a este, o esteatito típico, vulgo pedra-sabão. Os cristais formam romboedros mais ou menos idiomórficos de tamanho muito variável, desde grãos finíssimos até com mais de $1 \mathrm{~cm}$. Nas amostras mais meteorizadas encontram-se normalmente só as cavidades romboédricas, muitas vezes preenchidas com hidróxidos de ferro. Os cristais sãos podem mostrar uma textura poiquilítica devido a inclusões de silicatos, via de regra, clorita. Quase nunca o carbonato apresenta uma geminação de pressão. Através da difratometria de raios $\mathrm{X} \mathrm{em}$ várias amostras, o carbonato foi determinado como sendo magnesita.

Muito raramente são encontrados minerais primários. Perto de Santo Antônio do Itambé ocorre um piroxenito relativamente inalterado. É composto de ortopiroxênio (enstatita-bronzita) e clinopiroxênio (dialágio?) em grãos de até $\pm 3 \mathrm{~mm}$. Particularmente, o ortopiroxçnio mostă uma extinçào ondulante e, freqücntcmente, uma exsoluçào de lamelas finas de diopsídio. O clinopiroxênio não mostra pleocroísmo. Tanto o clino- como o ortopiroxênio encontram-se englobados numa matriz de minerais secundários, devido a uma uralitização.

Recentemente, Kehrer (no prelo) descreveu rochas ultrabásicas quase inalteradas ao sul de Senhora do Porto como sendo compostas de olivina, ortopiroxênio (enstatita-bronzita) e clinopiroxênio. Além disso, elas apresentam um espinélio verde, provavelmente hercynita, que pode atingir até $10 \%$ em volume. Pode ser classificada essa ocorrência como pertencente à família dos peridotitos.

A rocha acima forma uma camada com cerca de $30 \mathrm{~m}$, sendo intercalada mais ou menos concordantemente em biotita-gnaisses decompostos. No seu contato inferior, aflora uma camada de biotitito de 3 a $5 \mathrm{~m}$ de espessura. Esta é composta de palhetas com cerca de $5 \mathrm{~mm}$, de coloração marron, às vezes esverdeada. $O$ biotitito também deve pertencer ao clã dos ultrabasitos.

Metamorfismo Quanto ao grau de metamorfismo das rochas ultrabásicas, existe plena conformidade com o das rochas encaixantes. A maioria das ocorrências está localizada na zona da fácies de xisto verde médio, cuja associação típica é:

$$
\text { clorita + talco }+ \text { tremolita }+ \text { carbonato } \pm \text { antigorita } \pm \text { epídoto. }
$$


Leucoxênio, quartzo e opacos encontram-se como minerais acessórios. É notável a ausência de feldspato. O metamorfismo das rochas encaixantes é representado pelas seguintes paragêneses:

$$
\begin{gathered}
\text { quartzo + albita }+ \text { moscovita }+ \text { clorita }+ \text { microclínio-pertita e } \\
\text { quartzo }+ \text { albita }+ \text { moscovita }+ \text { biotita }+ \text { epídoto }+ \text { microclínio-pertita }
\end{gathered}
$$

Com o metamorfismo crescendo rumo a leste, os ultrabasitos apresentam a associação:

$$
\text { cloritat + talco + antofilita + tremolita + carbonato, }
$$

e as encaixantes são caracterizadas pelos seguintes minerais:

quartzo + andesina-oligoclásio + moscovita + biotita + almandina + estaurolita + + cianita.

Petrogênese A formação e a substituição dos respectivos minerais deixam concluir o esquema evolucionário da petrogênese das rochas ultrabásicas que apresentamos a seguir.

1. ${ }^{a}$ fase

Deu-se uma intrusão de peridotitos e piroxenitos durante um evento magmático no geossinclinal Minas. Foi acompanhada de extrusões sinsedimentares de material de básico a ácido, que foi conservado como xisto verde e anfibolito, filito hematítico e metariolitos (Renger, 1970a; 1970b). Segundo o esquema de Stille, pode ser classificado como magmatismo inicial. A maior concentração de magmatitos encontra-se na zona de transição entre as facies mio- e eugeossinclinal, onde os magmas intrudiram ao longo de falhas de tensão. Trata-se de uma ocorrencia do tipo alpino 'Thayce, 1960; Wyllie, 1968).

$2 .^{a}$ fase

Houve uma serpentinização relativamente logo após ou mesmo junto à intrusão, porém antes do paroxismo tectônico do geossinclinal. Essa fase também é conservada apenas em remanescentes, normalmente de tamanho microscópico. É bem possível que a serpentinização tenha sido causada por um autometamorfismo junto ao deslocamento dos corpos de ultrabasitos para a sua posição atual.

$3 .^{a}$ fase

Os ultrabasitos serpentinizados, sofrendo o metamorfismo regional da orogênese Minas, foram alterados mais uma vez, sendo as principais reações uma cloritização e anfibolitização, conforme o grau de metamorfismo que atingiu a respectiva região. Foram neoformadas clorita, tremolita-actinolita, antofilita, etc. A formação de clorita exige uma adição de alumínio. Isso poderia ser explicado através de duas hipóteses:

1) o alumínio foi liberado em conseqüência da alteração de feldspatos de rochas gabróides, acompanhando as intrusoes dos ultrabasitos. Outros inclícios para essa hipótese não foram encontrados;

2) o alumínio foi adicionado por um metassomatismo. As rochas encaixantes são ricas em alumínio, como pode ser visto na ocorrência de cianita, estaurolita e moscovita.

Essa questão não pode ser respondida ainda, exigindo pesquisa mais pormenorizada, incluindo um estudo da composição química. 
$4 .^{a}$ fase

O último evento reconhecível na petrogênese dos ultrabasitos é uma talquificação e carbonatização. Trata-se de um evento pós-tectônico. $\mathrm{O}$ processo é devido a um metassomatismo que trouxe o $\mathrm{CO}_{2}$ e lixiviou o ferro das cloritas e provavelmente outros elementos metálicos. Essa fase ocorreu possivelmente junto à formação dos pegmatitos na zona leste adjacente, fornecendo as soluções metassomáticas.

Mineralização Vários maciços das rochas ultrabásicas apresentam uma mineralização. Dos minerais primários de interêsse econômico encontra-se somente a cromita. São conhecidas ocorrências nas vizinhanças de Santo Antônio do I també, Serro, Alvorada de Minas e Dom Joaquim. Alves (1952) refere-se à ocorrência de cromo na região de Morro do Pilar e, segundo Dorr e Barbosa (1963), cromita é encontrada a SO de Itabira (veja Fig. 1). A ocorrência de Serro já foi estudada pelo DNPM (Alves, 1966; 1967).

$\mathrm{O}$ cromitito encontra-se normalmente encaixado em talco-clorita-xistos e forma corpos mais ou menos irregulares que possuem uma espessura variável entre, aproximadamente, 1 e $10 \mathrm{~m}$, por vezes orientados segundo a xistosidade da rocha encaixante (Fig. 4).

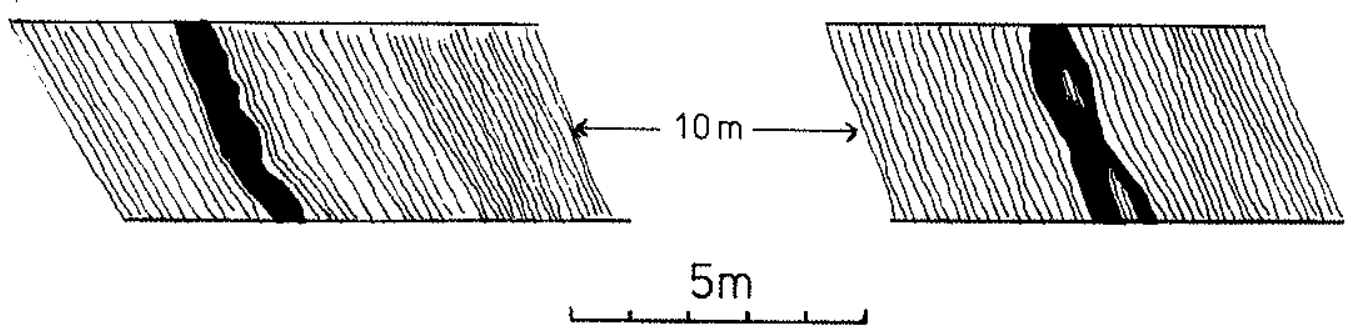

Figura 4 - Corpos de cromitito intercalados em talco-clorita-xisto; a cerca de $8 \mathrm{~km} \mathrm{~S}$ de Serro, MG (veja também a Fig. 2)

Os grãos de cromita são normalmente pequenos com um diâmetro aproximado de 0,1 a $0,5 \mathrm{~mm}$, muitos apresentando-se subidiomórficos, por vezes mostrando fenômenos de uma corrosão magmática. Com freqüência, eles são fortemente fragmentados por uma cataclase (veja a Fig. 5). A cromita é muito rica em ferro, especialmente nas bordas e ao longo de fissuras, devido a um enriquecimento de ferro durante o metamorfismo. $\mathrm{O}$ teor de $\mathrm{Cr}_{2} \mathrm{O}_{3}$ normalmente não atinge $40 \%$.

A distribuição dos afloramentos de cromitito deixa esperar um maior número de ocorrências a serem encontradas através de uma pesquisa sistemática.

Outra mineralização muito comum em ultrabasitos é o niquel, o que támbém já foi assinalado na região (Oliveira, 1966; 1967). Os melhores enriquecimentos são os sulfetos da diferenciação magmática ou os minerais secundários da serpentinização. Sulfetos primários não ocorrem na região.

O principal mineral silicático do níquel é a garnierita, pertencendo à serpentina. Porém, como já foi mencionado, os serpentinitos estão conservados somente em relíquias, sendo alterados quase completamente para rochas cloríticas ou esteatitos pelos processos das fases 3 e 4 , bastante desfavoráveis para um enriquecimento econômico.

Outro metal associado às rochas ultrabásicas é a platina, há muito tempo conhecida na região (Hussak, 1906). É encontrada somente em concreções aluvionares e havia sido explorada em pequena escala. O modo de ocorrência e a associação mineralógica nas rochas primárias não são conhecidos, porém pode-se admitir sua origem nas rochas ultrabásicas (Belezkij e Guimarães, 1959). 


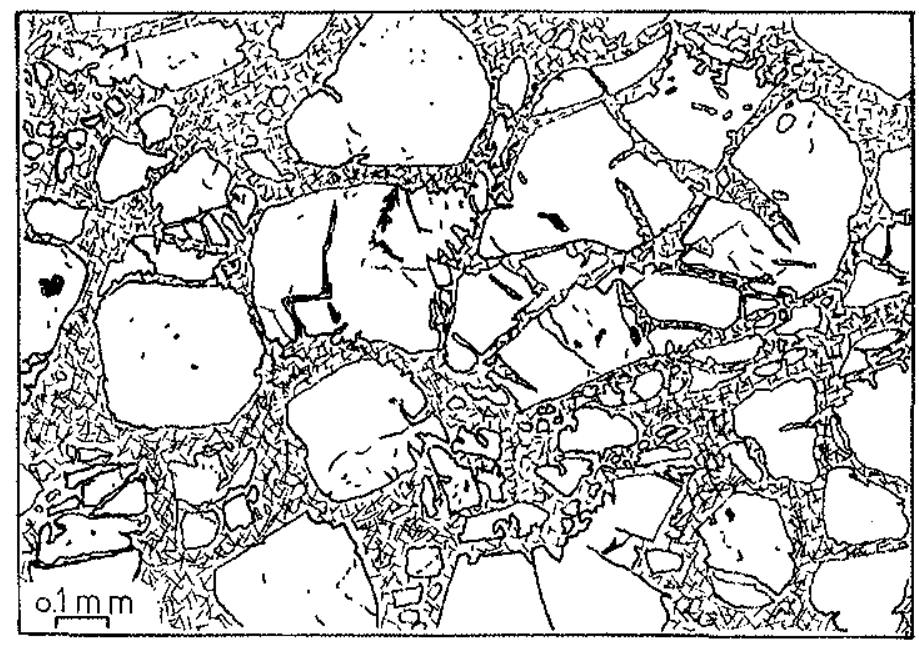

Figura 5 - Cromita (claro), intensamente cataclasada, numa matriz de clorita cromífera (kämmere rita). Procedência: a cerca de $500 \mathrm{~m} \mathrm{~N}$ de Serro, MG (veja também a Fig. 2)

Entre as mineralizações, devemos citar ainda o diamante, a riqueza mais famosa da Serra do Espinhaço. Ele é encontrado especialmente nos conglomerados intraformacionais da Série Minas, os quais foram depositados mais ou menos contemporâneos ao paroxismo magmático. Porém isso deve ser puro acaso, pois se encontra como rocha matriz dos diamantes, quase que exclusivamente, o kimberlito sob forma de chaminé. As chaminés, entretanto, são típicas para as áreas estabilizadas e anorogênicas. Os ultrabasitos da Serra do Espinhaço pertencem ao chamado tipo alpino, i.e., orogênico.

Correlação regional $\mathrm{Na}$ continuação da faixa ultrabásica da Serra do Espinhaço encontram-se ultrabasitos no Quadrilátero Ferrífero (Dorr, 1969) mostrando as mesmas características - tamanho, petrografia e a posição junto aos quartzitos e itabiritos. Muitas vezes, encontram-se intercalados ou associados com xistos verdes. A maioria deles é considerada como pertencente ao Grupo Nova Lima da Série Rio das Velhas. Nos arredores de Congonhas do Campo, os xistos verdes ocupam uma extensa área e formam as rochas encaixantes dos ultrabasitos, sendo que Guild (1960) já discutiu a sua posição estratigráfica e considerou-os como pertencentes à Série Minas. Com as novas evidências do magmatismo geossinclinal da Série Minas (Renger, 1970a; 1970b), as rochas ultrabásicas bem como os xistos verdes associados devem ser considerados como pertencentes à parte basal da Série Minas.

A escassez de ultrabasitos entre Morro do Pilar c Itabira deve ter sido causada por un anticlinório da Séric Pré-Minas ou Série Rio das Velhas (Dorr, 1969), Provavelmentc a faixa ultrabásica passe a leste, contornando esse anticlinório (Fig. 1).

A continuação da faixa para o norte é desconhecida por falta de mapeamentos numa cscala adequada. Somente a cerca de $700 \mathrm{~km}$ distante, na Serra de Jacobina, Bahia, cxnste uma outra província ultrabásica.

Essas ocorrências, contendo também cromita em vários locais, por exemplo, Campo Formoso, Saúde e Santa Luz, têm uma posição geológica quase idêntica em relação aos quartzitos que podem ser correlacionados com a Série Minas (Pflug el al., 1969). 


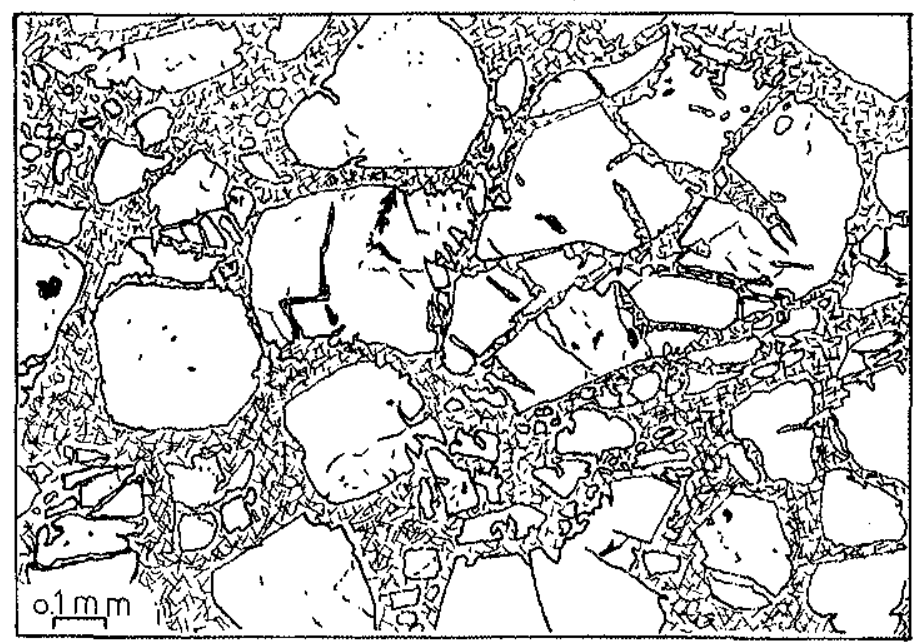

Figura 5 - Cromita (claro), intensamente cataclasada, numa matriz de clorita cromífera (kämmererita). Procedência: a cerca de $500 \mathrm{~m} \mathrm{~N}$ de Serro, MG (veja também a Fig. 2)

Entre as mineralizações, devemos citar ainda o diamante, a riqueza mais famosa da Serra do Espinhaço. Ele é encontrado especialmente nos conglomerados intraformacionais da Série Minas, os quais foram depositados mais ou menos contemporâneos ao paroxismo magmático. Porém isso deve ser puro acaso, pois se encontra como rocha matriz dos diamantes, quase que exclusivamente, o kimberlito sob forma de chaminé. As chaminés, entretanto, são típicas para as áreas estabilizadas e anorogênicas. Os ultrabasitos da Serra do Espinhaço pertencem ao chamado tipo alpino, i.e., orogênico.

Correlação regional $\mathrm{Na}$ continuação da faixa ultrabásica da Serra do Espinhaço encontram-se ultrabasitos no Quadrilátero Ferrífero (Dorr, 1969) mostrando as mesmas características - tamanho, petrografia e a posição junto aos quartzitos e itabiritos. Muitas vezes, encontram-se intercalados ou associados com xistos verdes. A maioria deles é considerada como pertencente ao Grupo Nova Lima da Série Rio das Velhas. Nos arredores de Congonhas do Campo, os xistos verdes ocupam uma extensa área e formam as rochas encaixantes dos ultrabasitos, sendo que Guild (1960) já discutiu a sua posição eștratigráfica e considerou-os como pertencentes à Série Minas. Com as novas evidências do magmatismo geossinclinal da Série Minas (Renger, 1970a; 1970b), as rochas ultrabásicas bem como os xistos verdes associados devem ser considerados como pertencentes à parte basal da Série Minas.

A escassez de ultrabasitos entre Morro do Pilar e I labira deve ter sido causada por um anticlinório da Série Pré-Minas ou Série Rio das Velhas (Dorr, 1969). Provavelmente a faixa ultrabásica passe a leste, contornando esse anticlinório (Fig. 1).

A continuação da faixa para o norte é desconhecida por falta de mapeamentos numa escala adequada. Somente a cerca de $700 \mathrm{~km}$ distante, na Serra de Jacobina, Bahia, cxnste uma outra província ultrabásica.

Essas ocorrências, contendo também cromita em vários locais, por exemplo, Campo Formoso, Saúde e Santa Luz, têm uma posição geológica quase idêntica em relação aos quartzitos que podem ser correlacionados com a Série Minas (Pllug et al., 1969). 
Assim, essa faixa ultrabásica pode ser seguida em quase toda a extensão na margem oriental do crato Sanfranciscano desde o Quadrilátero Ferrífero até a Bahia, sempre localizada na zona de transição entre os quartzitos do miogeossinclinal e os gnaisses do eugeossinclinal.

\section{BIBLIOGRAFIA}

ALVES, B. P. - 1952 - Nota preliminar sobre os estudos realizados no Município de Conceição do Mato Dentro. DNPM, DFPM Bol. 93, pp. 103-106, Rio de Janeiro

ALVES, B. P. - 1966 - Regiào de Serro, MG: Bauxita, Níquel e Cromo, in Relatório da Dirctoria, 1965. DNPM, DFPM Bol, 123, pp. 80-82, Rio de Janeiro

ALVES, B. P. - 1967 - Cromo: Regiôes de Serro e Conceição do Mato Dentro, in Relatório da Diretoria, 1966. DNPM, DFPM Bol. 131, pp. 84-86, Rio de Janeiro

BARBOSA, O. - 1949 - Contribuição à geologia do centro de Minas Gerais. Min. e Met. 14: 3-14, Rio de Janeiro

BARBOSA, O. - 1954 - Evolution du géosynclinal Espinhaço. XIX Gongr. Greol. Int., fasc. 14, pp. 17-36, Alger

BELEZKIJ, V. e GUIMARÃES D. - 1959 - Sobre uma ocorrência singular de platina, e gcologia da parte central da Serra do Cipó. Notas à margem de "O paládio e a platina no Brasil", de E. Hussak. DNPM, DFPM Bol. 106, 102 pp., Rio de Janeiro

COSTA, M. T. da - 1962 - Gênese e ocorrência da bauxita no Serro e regióes vizinhas, Minas Gerais. SICEG, II Semana de Estudos: Alumínio e Zinco, pp. 3-24, Ouro Preto

DOOR, J. V. N., II - 1969 - Physiographic, stratigraphic, and structural development of the Quadrilátero Ferrífero, Minas Gerais, Brazil. U.S. Geol. Surv. Prof. Pap. 64l-A, 110 pp., Washington

DORR, J.V. N., II C BARBOSA A. L. do M. - 1963 - Geology and ore deposits of the Itabira district, Minas Gerais, Brazil. U. S. Geol. Surv. Prof. Pap. 34l-A, 110 pp., Washington

EBERLE, W. Petrographische und geologische Untersuchungen in der Umgebung von Diamantina, Espinhaço Zone, Minas Gerais, Brasilien. Geol. Jahrb., Bh. 121 (no prelo)

FRANK, R. - 1971 - Geologie des nordlichen Serra Mineira (südliche Espinhaço-Kordillere, Minas Gerais, Brasilien). Tese de Diploma, Univ. Heidelberg, 42 pp.

GORLT, G. Fazieswechsel und Metamorphose in der westlichen Serra Negra (Espinhaço-Zone, Minas Gerais, Brasilien). Geol. Rundschau (no prelo)

GUILD, P. W. - 1960 - Gologia e recursos minerais do distrito de Congonhas, Estado de Minas Gerais, traduzido por A. L. de M. Barbosa. DNPM, Mem. 1, 217 pp., Rio de Janeiro

HUSSAK, E. - 1906 - Über das Vorkommen von Palladium und Platin in Brasilien. Zeitschr. f. prakt. Geol. 14: 284-293, Halle

KEHRER, P. Zur Geologie der Itabirite in der südlichen Serra do Espinhaço (Minas Gerais, Brasilien). Geol. Rundschau (no prelo)

MORAES, L. J. de - 1937 - Geologia geral, in Geologia econômica do Norte de Minas Gerais. DNPM, SFPM Bol. 19 pp. 7-111, Rio de Janeiro

PFLUG, R. - 1965 - A geologia da parte meridional da Serra do Espinhaço e zonas adjacentes, Minas Gerais. DNPM, DGM Bol. 226, 51 pp., Rio de Janeiro

PFLUG, R. - 1967 - Die präkambrische Miogeosynklinale der Espinhaço-Kordillere, Minas Gerais, Brasilien. Geol. Rundschau 56: 825-844, Stuttgart

PFLUG, R., SCHOBBENHAUS G. \& RENGER F. - 1969 - Contribuição à geotectônica do Brasil Oriental. Contribution to the geotectonics of east Brazil. SUDENE, DER, Div. Geol., Ser. Espec. 9, 57 pp., Recife

RENGER, F. - 1970a - Fazies und Magmatismus der Minas-Série in der südlichen Serra do Espinhaço, Minas Gerais, Brasilien. Geol. Rundschau 59: 1253-1292, Stuttgart

RENGER, F. - 1970b - O magmatismo geossinclinal do Grupo Minas. XXIV Gongr. Bras. Geol., Bol. Espec. 1, pp. 190-193, Brasilia 
SCHMIDT, H. L. Fazieswechsel in der São Francisco-Série (Bambuí) bei Bocaiúva, Espinhaço-Zone, Minas Gerais, Brasilien. Geol. Jahrb., Bh. 121 (no prelo)

SGHÖLL, W. Der südwestliche Randbereich der Espinhaço-Zone, Minas Gerais, Brasilien - Geol. Rdsch. (no prelo)

SCORZA, E. P. - 1968 - Distribuição das rochas ultrabásicas no Brasil. An. Acad. Bras. Ciênc., 40 (supl.), pp. 119-126, Rio de Janeiro

THAYER, T. P. - 1960 - Some critical differences between alpine-type and stratiform peridotite-gabbro complexes. XXI Int. Geol. Congr., Repts. 13, pp. 247-259, Gopenhagen

WYLLIE, P. J. - 1968 - The origin of ultramafic and ultrabasic rocks. XXIII Int. Geol. Congr., Upper Mantle Symposium, 34 pp., Praga (mimeografado) 